\title{
USO DE CURVAS DE ISOVALORES DE PARÂMETROS FÍSICOS E QUÍMICOS PARA A CARACTERIZAÇÃO DE SISTEMAS PEDOLÓGICOS DESENVOLVIDOS SOBRE ROCHAS BÁSICAS NAS REGIÕES NORTE E SUL DO BRASIL
}

\author{
GERALDO CÉSAR ROCHA ${ }^{a}$
}

\section{RESUMO}

Propõe-se neste trabalho o uso de curvas de isovalores para representar a distribuição espacial de características físicas e químicas de coberturas pedológicas ao longo de vertentes. A utilização destas curvas, testadas em sistemas pedológicos das regiões Norte e Sul do Brasil, mostrou-se útil para se visualizar a dinâmica de parâmetros como os percentuais de argila, silte e areia, assim como o pH, Capacidade de Troca de Cátions e Soma de Bases dos solos estudados. Foi possível correlacionar o comportamento das curvas de isovalores com a variação pedológica ao longo das encostas.

PALAVRAS-CHAVE: Sistemas pedológicos, Curvas de isovalores, Topossequências de solos.

\section{1 - INTRODUÇÃO}

O estudo da distribuição dos solos na paisagem evoluiu a partir da noção de topossequências, Moniz \& Buol (1982), Rocha (1982). Entretanto a noção de topossequências como um modelo de organização pedológica, no qual os tipos de solos variam de acordo com sua posição topográfica, apresenta o inconveniente de considerar a cobertura pedológica de maneira segmentada, formada por tipos distintos de solos distribuídos na encosta, e não de maneira continua como ela verdadeiramente é.

O estudo da inter-relação dos solos na paisagem pode ser feito de maneira mais abrangente utilizando-se do enfoque de sistemas pedológicos. Entende-se por sistema pedológico todo conjunto estruturado de volumes ou horizontes pedológicos que correspondem à seqüências de organizações elementares ordenadas no espaço e no tempo, Lucas (1989); a ordenação dos horizontes pedológicos no espaço pode ser compreendida levando-se em conta a seqüência normal destes horizontes, na qual o horizonte A está sobreposto ao B e este ao horizonte C. Já sua ordenação temporal diz respeito à evolução de um perfil de solo no tempo, na qual primeiramente se forma o horizonte A e em seguida o B; também é possível se estabelecer relações temporais entre o horizonte B textural e o B latossólico. A caracterização do sistema pedológico é feita através de análises físicas, químicas e mineralógicas, usando-se métodos sofisticados como microscopia eletrônica e microsonda para um detalhamento analítico das características pedológicas. Com relação aos dados físicos e químicos dos solos estudados, principalmente com relação a estes últimos, não se nota nos trabalhos publicados uma visualização integrada dos mesmos ao longo da vertente, o que facilitaria o entendimento e inter-relação dessas características com os demais componentes do sistema pedológico.

O objetivo desse trabalho é mostrar que a utilização de curvas de isovalores para as características físicas e químicas de solos distribuídos ao longo de sistemas pedológicos contribui para uma visualização mais abrangente da distribuição dessas características ao longo do sistema pedológico, assim como facilita o estudo das causas dessa distribuição.

\section{2 - METODOLOGIA}

Estudaram-se sistemas pedológicos desenvolvidos sobre rochas básicas e em topografias semelhantes, mas em regiões de clima e vegetação atuais distintas do Brasil. Escolheram-se em cada uma dessas regiões seqüências de solo representativas ao longo de vertentes de extensão média de 1000 metros situadas sobre rochas básicas. Na Região Norte a área de estudo situa-se na Amazônia, estado do Pará, à altura do km 100 da Rodovia Transamazônica. O clima está classificado como tropical úmido, com temperatura média anual de $26^{\circ} \mathrm{C}$ e pluviosidade de $1680 \mathrm{~mm}$ por ano; o relevo é de planalto, com altitude média de 150 metros e relevo suave ondulado a ondulado. A vegetação é a Floresta Equatorial, sendo a geologia caracterizada por diabásios mesozóicos. Ao sul, a pesquisa foi desenvolvida no campus da Universidade Estadual de Londrina, ao norte do estado do Paraná. O clima é subtropical úmido com temperatura anual média de $22,5^{\circ} \mathrm{C}$ e pluviosidade de $1615 \mathrm{~mm}$ anuais. O relevo tem altitude média de 550 metros, constituindo-se de planalto no qual a topografia mostra formas 
que variam de suave onduladas a onduladas. A vegetação é uma Floresta Tropical, sendo a geologia formada por basaltos mesozóicos da Formação Serra Geral.

A caracterização morfológica dos solos no campo abrangeu em cada área o estudo de três perfis ao longo das vertentes representativas, através da abertura de trincheiras principais, cada qual com profundidade de dois metros e localizadas respectivamente no topo, meia encosta e sopé da vertente, segundo critérios de Boulet et al (1982); entre estas três trincheiras principais foram feitas tradagens para checar as transiçSes entre os solos; a descrição dos perfis, feita segundo a metodologia proposta por Lemos \& Santos (1984), permitiu a visualização do encadeamento espacial dos horizontes ou volumes pedoiógicos. Para as análises foram coletadas amostras sistemáticas ao longo das três trincheiras principais, da superfície até a profundidade de dois metros.

\section{Análises físicas}

As análises físicas foram feitas em solos e alteritas das topossequências em estudo; as amostras foram secas a temperatura ambiente e passadas, em peneira de $2 \mathrm{~mm}$, obtendo-se a terra fina seca ao ar (TFSA).

\section{Granulometria}

Foi usado o método da pipeta, empregando-se como dispersante o hidróxido de sódio, em agitação por 16 horas em garrafas de Stohman; pipetou-se silte e argila, tendo sido a areia separada em peneira. Para a determinação da argila natural usou-se a água destilada.

\section{Análises químicas}

Para as amostras de solo foram feitas as caracrerizações químicas listadas a seguir, usando-se a TFSA.

pH: em água destilada e $\mathrm{KCl}^{-} \mathrm{N}$, usando-se a relação 10 gramas de solo para $25 \mathrm{ml}$ de água ou $\mathrm{KC} 1$, com leitura em peagâmetro.

Carbono é Nitrogênio totais: usando-se 1 grama de solo peneirado a 100 mesh, com leitura em aparelho LECO CHN 600. Para a curva sistemática do carbono, as determinações foram feitas em aparelho Carmograph (combustão seca). Foram calculados os estoques acumulados de carbono dos solos.

$\mathrm{Ca}++, \mathrm{Mg}++, \mathrm{Na}+$ e $\mathrm{K}+$ : usando-se extrator $\mathrm{HC} 10,05$ $\mathrm{N}$ e relação $1 / 10$ entre material e solução extratora, com leitura em espectrofotômetro de absorção atômica.

Valor S (soma de bases): feito por cálculo, resultante da somatória das bases $\mathrm{Ca}++, \mathrm{Mg}++, \mathrm{Na}+\mathrm{e} \mathrm{K}+$.

$\mathrm{H}+$ + $\mathrm{A} 1+++$ (acidez potencial): avaliação pela depressão causada no pH de solução tampão, mediante curva de correlação entre valores do pH dá solução tampão e valores de acidez potencial determinados pelo método do acetato de cálcio (método SMP - IAC).

Capacidade de Troca de Cátions (CTC): feita por cálculo, resultante da somatória do valor $\mathrm{S}$ com a acidez po- tencial (CTC a pH 7).

Valor V (percentual de saturação de bases): feito por cálculo, através da fórmula $\mathrm{V}=\mathrm{S} .100 / \mathrm{CTC}$

De posse dos dados físicos e químicos dos solos estudados foram confeccionadas as curvas de isovalores desses dados ao longo das encostas, as quais são feitas interpolando-se pontos de isoteores de cada perfil e entre perfis de solos ao longo da paisagem.

\section{3 - RESULTADOS E DISCUSSÃO}

A caracterização morfológica dos perfis de solos ao longo das encostas, feita através dos dados obtidos nas trincheiras, assim como nas tradagens efetuadas, permitiu a confecção de cortes transversais das vertentes, nos quais pode-se observar a distribuição espacial dos volumes pedológicos nas duas áreas, figura 1. Nota-se que para as duas regiões os volumes principais são o B latossólico e o B textüral, os quais apresentam comportamento semelhante nas duas áreas estudadas: o horizonte B latossólico predomina no topo da encosta, enquanto o horizonte B textural está mais distribuído na parte mais declivosa dà vertente. Para cada região estudada fez-se as curvas de isovalores das características físicas e químicas ao longo das vertentes.
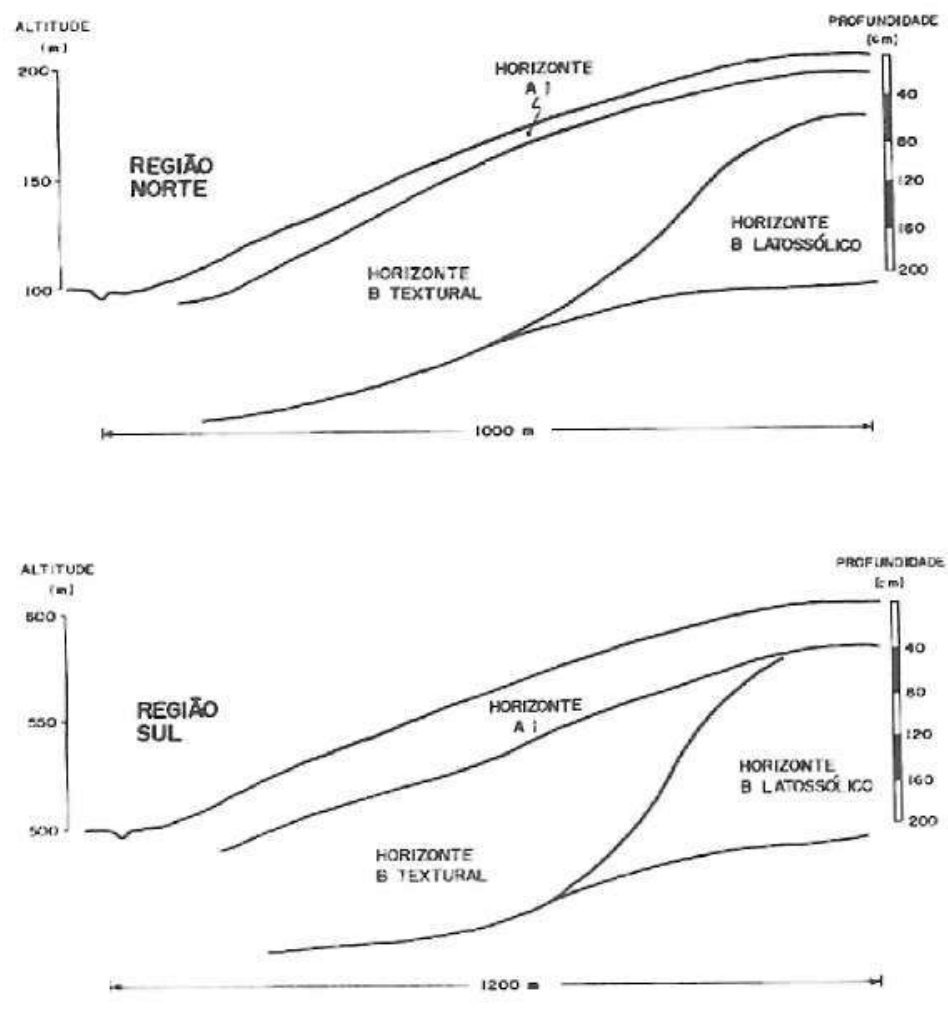

FIGURA 1 - Distribuição espacial dos volumes pedoiógicos nas áreas estudadas 


\section{te}

Sistema pedológico sobre rocha básica da Região Nor-

De modo a facilitar a visualização do comportamento dos teores de areia, silte e argila ao longo da vertente, fez-se as curvas de isoteores para essas subfrações ao longo da seqüência, figura 2.

Pode-se observar que:

a) a fração areia diminui tanto em direção jusante como em direção aos horizontes mais profundos do solo de sopé; b) a fração silte diminui à jusante até um mínimo de $22 \%$ em profundidade na meia encosta, aumentando em seguida em direção ao vale, e

c) a fração argila aumenta à jusante, atingindo um máximo de $60 \%$ a $150 \mathrm{~cm}$ de profundidade, diminuindo em seguida em direção ao sopé.

É interessante constatar nos trabalhos feitos na região, que também o teor de argila total para solos semelhantes raramente ultrapassa os $60 \%$, Divisão de Pesquisas Pedológicas (1973), Kitagawa \& Moller (1979), fato que está ligado- a um aumento relativo dos teores de areia para os solos da região.

Para facilitar a visualização do comportamento de algumas características químicas ao longo da cobertura pedológica estudada na Região Norte, fez-se as curvas de isovalores para a soma de bases, CTC a $\mathrm{pH} \mathrm{7,} \mathrm{pH} \mathrm{em} \mathrm{água} \mathrm{e} \mathrm{pH}$ em $\mathrm{KC} 1$, figura 3.

Nota-se que o valor $\mathrm{S}$ e a CTC a pH 7 apresentam tendência semelhante, com valores mais elevados ao longo da superfície da encosta, decrescendo em profundidade, mas atingindo um teor mínimo localizado em profundidade na meia encosta.
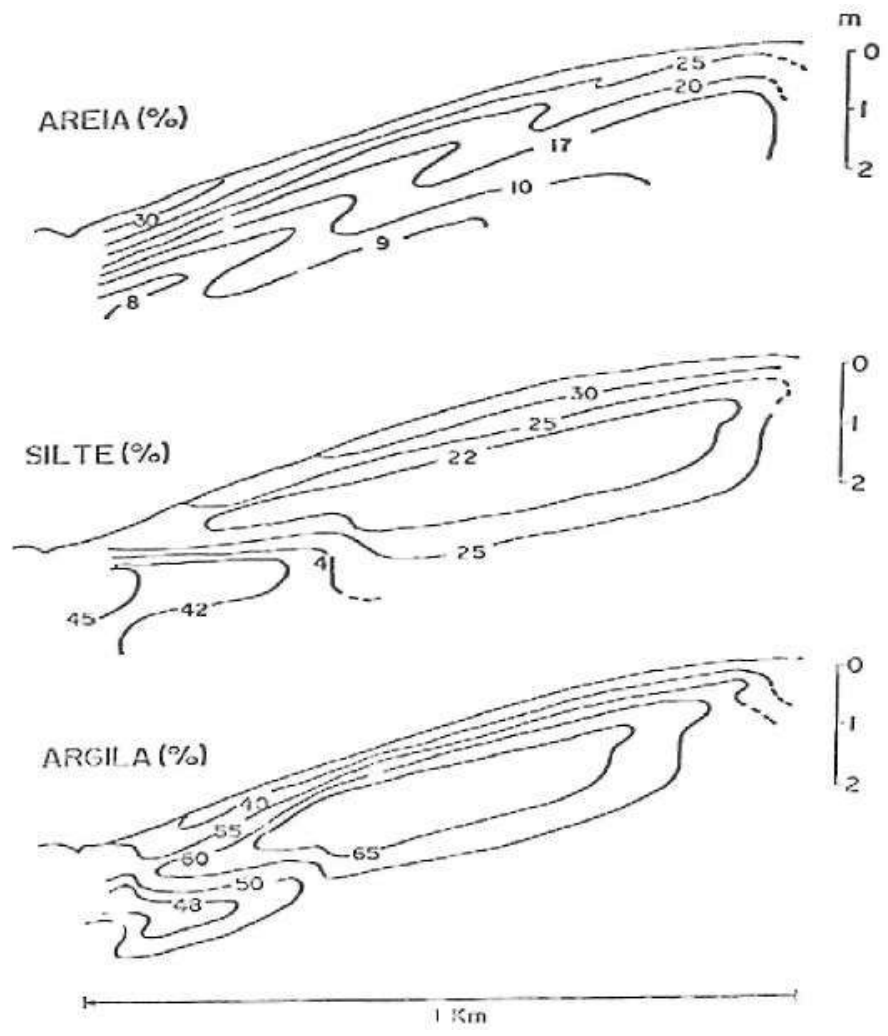

FIGURA 2 - Curvas de isoteores das características físicas para o sistema pedológico da Região Norte.
$\mathrm{O}$ pH em água sofre um decréscimo inicial a partir do topo, até atingir um mínimo na profundidade média da meia encosta, aumentando em seguida à jusante.

Já o pH em KCl diminui à jusante, atingindo um mínimo na profundidade média do sopé da encosta, voltando a crescer em seguida, em direção às camadas mais profundas.
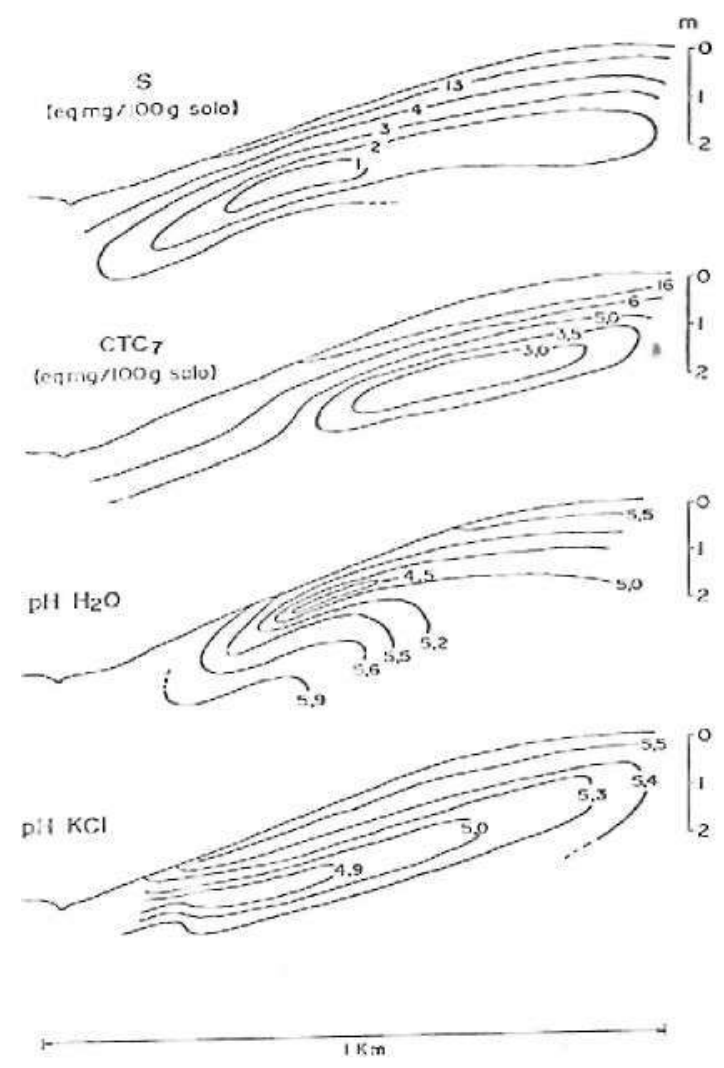

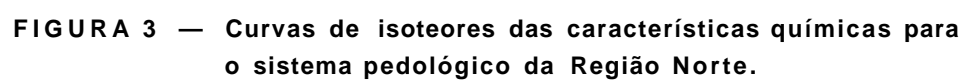

Variação das características físicas e químicas no sistema pedológico

As curvas de isoteores de areia, silte e argila mostradas na figura 2 ilustram o comportamento dessas subfrações ao longo do sistema pedológico da Região Norte. Nota-se concordância entre essa distribuição e o posicionamento espacial dos volumes pedológicos anteriormente definidos.

Com relação à areia total verifica-se um teor mais elevado dessa subfraçâo ao longo das camadassuperficiais da cobertura pedológica, o que está coerente com os maiores teores de quartzo observados ao microscópio ótico para o volume pedológico representado pelo horizonte A, já que se sabe que o quartzo é o mineral predominante na fração areia desse material, Rocha (1990).

Nota-se que a diminuição vertical da areia em profundidade na parte alta e na meia encosta é gradual. No sopé essa variação é brusca, o que é atestado pela proximidade das isolinhas nesse local. Assim, pode-se admitir com base em Birkeland (1974) e Hall (1984), uma concentração residual do mineral resistente desta fração na maior parte da encosta devida à evolução pedogenética; no sopé da vertente, entretanto, pode ter havido aporte externo de sedimen- 
tos por erosão de matéria) à montante, o que explicaria a maior concentração de areia em superfície $(30 \%)$, a qual decai de modo relativamente rápido para $8 \%$ em profundidade.

Quanto ao silte, observa-se que o teor mínimo dessa subfração, em torno de $22 \%$, está praticamente distribuído ao longo do volume representado pelo horizonte B textural (figura 1); esse fato também se verifica para o teor máximo de argila $(65 \%)$, o que mostra a estreita relação entre essas duas subfrações e o horizonte B textural. O acúmulo de argila nessa zona da cobertura pedológica da Região Norte parece estar relacionada aos processos de gênese do horizonte argílico, como constatou Eswaran (1972) estudando esse tipo de mecanismo, o qual se caracteriza pelo acúmulo da subfração argilosa, o que foi constatado pela micromorfologia.

Boulet et al (1982) também constataram correlação entre as curvas de isoteores de argila e volumes pedológicos argilosos, concluindo que tais volumes avançam em direção montante como resultado da evolução de sistemas pedológicos em transformação.

Por outro lado constata-se que os menores teores de argila e areia, e consequentemente os maiores valores de silte, concentram-se no volume mosqueado situado em profundidade no sopé da encosta, fato que também mostra a íntima correlação entre os componentes granulométricos e os volumes pedológicos do sistema da Região Norte.

As características químicas estudadas, resumidas nas curvas de isovalores da figura 3 , mostram que para o sistema pedológico da Região Norte não são as argilas minerais, mas sim a matéria orgânica a principal responsável pelos maiores teores de bases, maior CTC e pH dos volumes pedológicos daquela região, como também verificaram Demattê (1988) e Martins (1987). A CTC e o valor S apresentam os maiores valores em superfície, principalmente nas partes mais altas da topografia; a menor reatividade e teor de bases do sistema estão localizados nas camadas profundas da cobertura pedológica onde estão os horizontes B latossóllco e B textural. Os valores de $\mathrm{pH}$ também mostram essa tendência, apesar de não ser tão clara para o pH em água. Entretanto, a maior variabilidade apresentada por esse $\mathrm{pH}$, como coloca Passbender (1984) para solos da América Latina, pode ser a explicação para tal comportamento.

\section{Sistema pedológico sobre rocha básica da Região Sul}

Também para a Região Sul foram feitas as curvas de isoteores para areia, silte e argila, figura 4. Verificou-se que: a) a areia aumenta em direção jusante;

b) o silte aumenta à jusante e em direção aos horizontes de superfície do solo de sopé, e

c) a argila diminui à jusante e em direção às camadas superficiais do sopé da encosta.

Como para a Região Norte fez-se as curvas de isovalores para algumas características químicas selecionadas da Região Sul, figura 5.

Observa-se que para a soma de bases (valor S) e CTC a
pH 7 as tendências são semelhantes ao longo da cobertura pedológica, isto é, as curvas de maiores valores concentramse em profundidade na meia encosta.

É interessante destacar a distribuição máxima bimodal ao longo do solo da meia encosta para as duas características mencionadas.

Para o pH em água a tendência observada é um aumento do valor dessa característica em direção jusante da encosta, com o valor mínimo em profundidade para o solo de topo.

Já o pH em $\mathrm{KC} 1$ apesar de se notar a mesma tendência de aumento à jusante, o valor mínimo se encontra na superfície do solo de topo de encosta.

Variação das características físicas e químicas no sistema pedológico

A figura 4 mostra o comportamento dos teores de areia, silte e argila ao longo do sistema pedológico da Região Sul. Nota-se uma distribuição gradual, na qual as invaginações características dessas isolinhas se sucedem de maneira regular, sem zonas de acúmulo ou de empobrecimento localizados ao longo da encosta.

As curvas de isoteores para as três subfrações mostram coerência com os volumes pedológicos definidos, ou seja: os maiores teores de argila, e consequentemente os menores percentuais de silte e areia, estão localizados no volu-

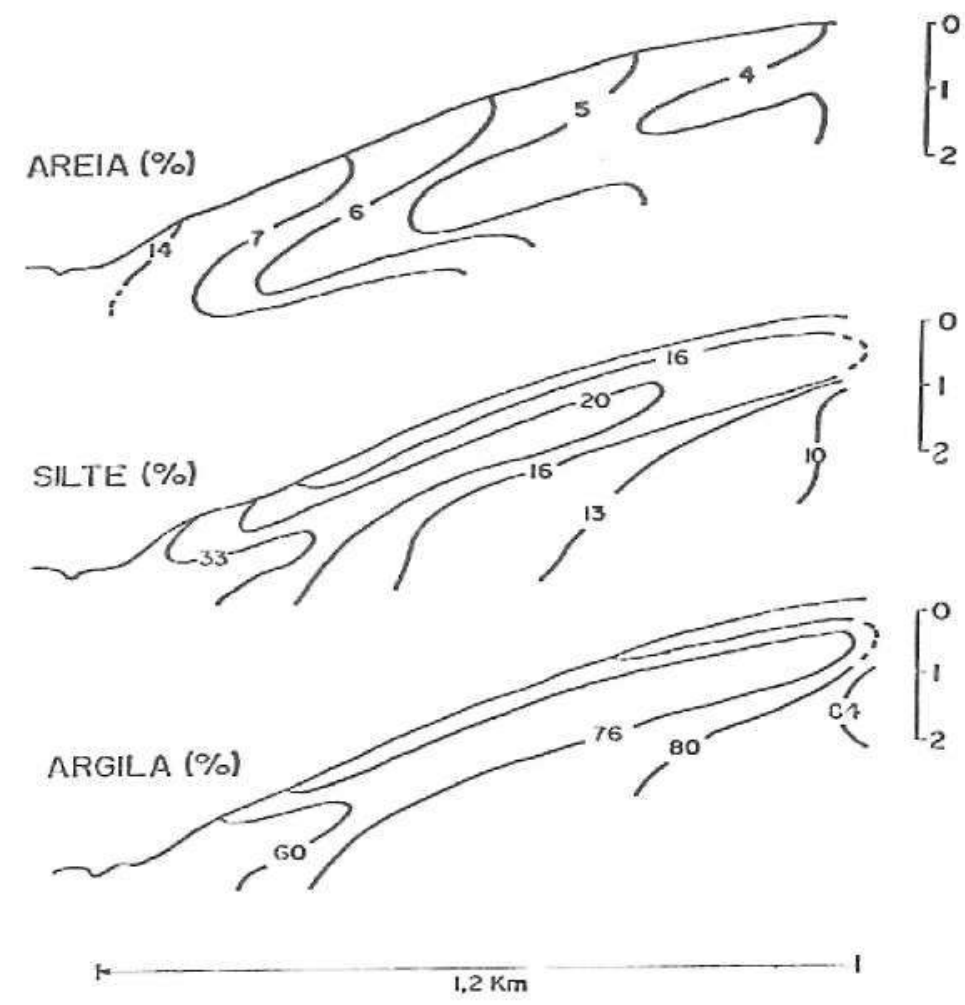

FIGURA 4 - Curvas de isoteores das características físicas para o sistema pedológico da Região Sul 


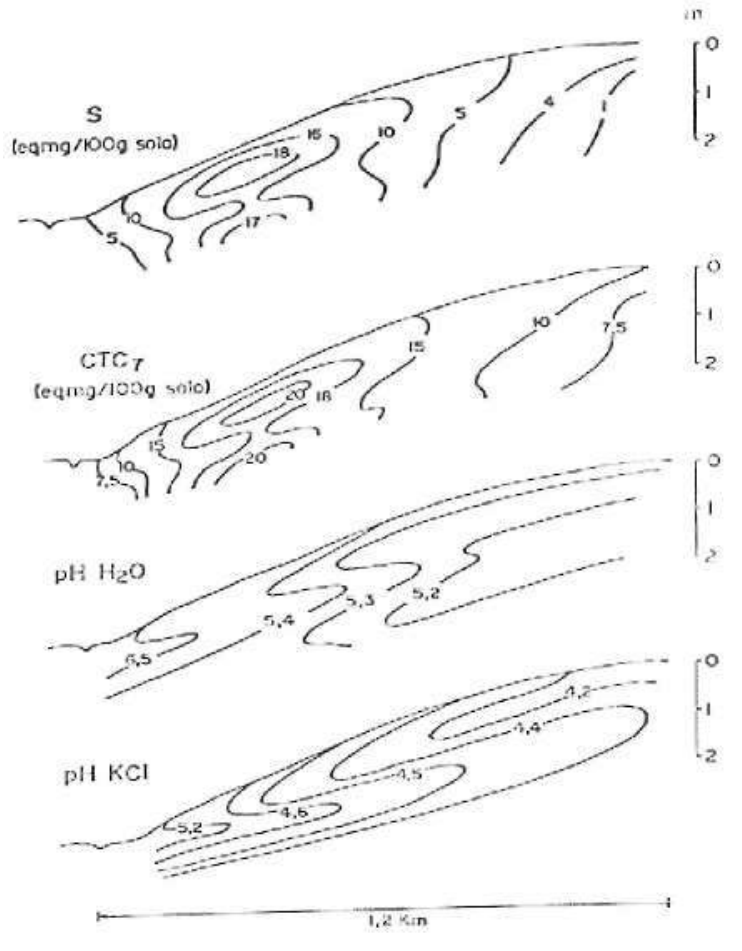

FIGURA 5 - Curvas de isoteores das características químicas para o sistema pedológico da Região Sul

me latossólico, o que é devido certamente ao avançado estágio intempérico desse material pedológico, como colocado por Lima (1979).

À medida que se desce na encosta observa-se um aumento nos teores de silte e areia, ao mesmo tempo que diminuem os percentuais de argila. Isso pode ser explicado pelo fato de que no sopé da encosta os processos pedogenéticos estão incipientes, com a presença de alteritas e ausência de horizontes B, fato que segundo Gonçalves (1987) condicionam um baixo teor de argila e percentuais mais elevados de areia e silte.

Lucas (1989) constatou um padrão semelhante para o comportamento das curvas de isoteores de argila de um sistema pedológico da região amazônica, atribuindo a essa feição uma das evidências de um sistema de transformação de um material latossólico no topo da encosta para um material podzolizado situado no sopé.

As curvas de isoteores confeccionadas para as características químicas selecionadas da Região Sul parecem indi- car que a matéria orgânica tem uma influência relativa, principalmente nos teores de bases e CTC dos volumes pedológícos estudados, sendo também relevante o papel do ambiente intempérico.

Os dados de carbono orgânico (*) em confronto com as isolinhas das características químicas, mostram que: 1. para o volume pedológico representado pelo horizonte $B$ textural, observa-se que o percentual de carbono orgânico, apesar de uma queda gradual em profundidade, ainda mantém percentuais da ordem de $1 \%$ a 2 metros; essa matéria orgânica, aliada a um ambiente lixiviante menos agressivo é provavelmente a responsável pelos altos valores da CTC e do valor $\mathrm{S}$ ao longo desse volume pedológico, como explicou Martins (1987); 2. para o volume latossólico, apesar da manutenção de um razoável teor de carbono orgânico mesmo em profundidade, a CTC e a soma de bases apresentam os menores valores do sistema da Região Sul; isto pode ser talvez explicado pela preponderância da agressividade intempérica dos ambientes oxídicos, como mostrou Birkeland (1974), sobre a capacidade de retenção dos compostos orgânicos, devido à uma alta taxa de lixiviação dos cátions básicos que acontece nesse tipo de solo.

$\mathrm{O}$ decréscimo gradual do $\mathrm{pH}$ em água e $\mathrm{KCl}$ em direção jusante do sistema explicar-se-ia também pelas características geoquímicas dos ambientes pedológicos do sistema, a saber, mais agressivo e lixiviante na cobertura de topo, e com tendência de uma maior concentração em cátions básicos nos volumes inferiores da seqüência, devido à proximidade do material de origem e menor grau evolutivo do material pedológico, como exemplificou Hall (1984) para solos semelhantes.

\section{5 - CONCLUSÃO}

O uso das curvas de isovalores de características físicas e químicas de sistemas pedológicos desenvolvidos sobrerochas básicas e situados em vertentes características das regiões norte e sul do Brasil permitiu uma visualização abrangente e contínua da distribuição dessas características ao longo das vertentes estudadas. Foi possível correlacionar a distribuição dessas características com parâmetros pedológicos: no sistema pedológico da Região Norte, verificou-se o papel da matéria orgânica como condicionador da química do solo. Na seqüência de solos estudada na Região Sul as características químicas estão ligadas principalmente ao ambiente intempérico atuante. Já a distribuição dos parâmetros físicos das duas regiões foi correlacionada com as feições pedogenéticas de cada área.

\section{ABSTRACT}

The utilization of isovalue curves is proposed to represent the spatial distribuition of physical and chemical characteristies of pedological covers. These curves are useful to visualize the landscape dynamics of parameters such as pH, CEC and base content, as well as the percentage of clay, silt and sand. It was possible to correlate the isovalue curves with the pedological variations along slopes.

KEY-WORDS: Pedological systems; Isovalue curves; Soil topossequences. 


\section{REFERÊNCIAS BIBLIOGRÁFICAS}

1 - BIRKELAND, P.W. Pedology, Weathering and Geomorphological Research, New York, Oxford University Press, 1974.

2 - BOULET, R.; CHAUVEL, A.; HUMBEL, F.X. \& LUCAS, Y. Analyse structurale et cartographie en pédologie. I. Prise en compte de l'organisation bidimensionnelle de la couverture pédologique: les études de toposéquences et leur principaux apports à la connaissance des sols. Cahiers ORSTOM série Pédologie, Paris, v. 19, n. 4 p. 309-321, 1982.

3 - DEMATTE, J. L. I. Manejo de solos ácidos dos trópicos úmidos Região Amazonica. Campinas, Cargill, 1988. 215 p.

4 - DIVISÃO DE PESQUISA PEDOLOGICA. Levantamento de reconhecimento dos solos de uma área prioritária na Rodovia Transamazônica entre Altamira e Itaituba. Boletim Técnico 34. Belém, 1973 c. (com mapa).

5 - ESWARAN, H. Micromorphological indicators of pedogenesis in some tropical soils derived from basalts from Nicaraguá. Geoderma; Amsterdam, v. 7, n. 1/2, p. 15-31, 1972.

6 - FASSBENDER, H.W. Quimica de Suelos - con énfasis en suelos de A merica Latina. San Jose, Costa Rica. Instituto Interamericano de Cooperacion para la Agricultura. 1984. $398 \mathrm{p}$.

7 - GONÇALVES, N.M.M. Transformaçбes mineralógicas e estruturais relacionadas d alteraçăo hidrotermal e intempérica de rochas vulcânicas básicas da Bacia do Paraná Setentrional (Regiāo de Ribeirão Preto - SP, Brasil). Såo Paulo: Instituto de Geociências/USP. 1987. 212 p. (Tese de Doutorado).

8 - HALL, G.F. Pedology and Geomorphology. In: WILDING, L.P.; SMECK, N.E. \& HALL, G.F. Pedogenesis and Soil Taxonomy. I. Concepts and Interactions. Amsterdam, Elsevier, 1984. cap. 5, p: 117-136.

9 - KITAGAWA, Y. \& MOLLER, R.F. Clay mineralogy of the "Terra Roxa Estruturada"soils from forest/savannah transition in the Amazon region. Soil Sc. \& Pl. Nutr. Japan, v. 25, n. 3, p. 397-405, 1979.

10 - LEMOS, R.C. \& SANTOS, R.D. Manual de descrição e coleta de solo no campo. Campinas: Soc. Br. Ci. Solo e Serv. Nac. Lev. Cons. Solos, 1984. 46 p.
11 - LIMA, V.C. Caracteristicas i: classificaçāo de solos derivados de enuptivas básicas do terceiro planalto paranaense. Piracicaba: ESALQ/USP, 1979. 249 p. (Tese Doutorado).

12 - LUCAS, Y. Systemes pedologiques en A mazonie bresilienne equilibres, desequilibres et transformations. Poitiers: Université de Poitiers. 1989. 158 p. (Tese de Doutorado).

13 - MARTINS, P.F.S. Propriedades de solos sob floresta natural e sua alteraçāo em consequência do desmatamento e cultivo, na Amazónia oriental. Piracicaba: ESALQ;USP. 1987. 232 p. (Tese de Doutorado).

14 - MONIZ, A,C \& BUOL, S.W. Formation of an Oxisol - Ultisol transition in Săo Paulo, Brazil: J. Double water flow model of soil development. S. Sc. Soc. A. J. . Madison, v. 46, n. 6, p. 1228-1233, 1982.

15 - ROCHA, G.C. Geologia, geomorfologia e pedologia de uma catene de solos situada no campus do Escola Superior de Agriculruro de Larvas, $M . G$. Lavras: ESAL. 1982.109 p. (Tese de Mestrado).

16 - ROCHA, G.C. Caracteristicas e Dinâmica de Coberturas Pedológicas sobre Rochas Básicas nas Regióes Norte e Sul do Brasil. ESALQ: Piracicaba, 1990 (Tese de Doutorado).

Recebido para publicação em 20/7/90 